\title{
Evaluation of Titanium and Titanium Oxides as Chemo-affinity Sorbents for the Selective Enrichment of Organic Phosphates
}

\author{
Akira SANO and Hiroshi NAKAMURA ${ }^{\dagger}$ \\ Faculty of Pharmaceutical Sciences, Tokyo University of Science, 2641 Yamazaki, Noda, Chiba 278-8510, Japan
}

\begin{abstract}
Titanium (Ti) and $\mathrm{TiO}, \mathrm{Ti}_{2} \mathrm{O}_{3}, \mathrm{Ti}_{3} \mathrm{O}_{5}$ and $\mathrm{TiO}_{1.98}$ as well as $\mathrm{TiO}_{2}$ have been evaluated as chemo-affinity sorbents for the selective enrichment of organic phosphates. A column-switching high-performance liquid chromatography (HPLC) system, constructed with a precolumn $(4.6 \mathrm{~mm}$ i.d. $\times 10 \mathrm{~mm})$ packed with the titanium sorbents, an anion-exchange analytical column and a UV detector $(215 \mathrm{~nm})$ was used. When an aqueous $0.015 \%$ trifluoroacetic acid (TFA) was used as a sample-loading solution, $O$-phospho-L-tyrosine (P-Tyr), phenyl phosphate and phenylphosphonic acid were adsorbed onto all of the titanium sorbents with recoveries of $60.9-102.9 \%$. Some acidic compounds other than phosphates, such as benzenedicarboxylic acid (BDA) isomers, were also adsorbed onto all of the titanium sorbents. To improve the selectivity to organic phosphates, various sample-loading solutions were examined using a Ti precolumn, two phosphorylated peptides [Ile-Ser(p)-Val-Arg (PP1) and Gln-Ile-Ser(p)-Val-Arg (PP2)], P-Tyr, BDA isomers and diglutamic acid (Glu$\mathrm{Glu}$ ) as test compounds. Among the sample-loading solutions tested, such as TFA, $\mathrm{HClO}_{4}$, organic acids, boric acid and $\mathrm{NaCl}$, the use of $100 \mathrm{mM} \mathrm{NaCl}$ in $10 \mathrm{mM}$ boric acid was found to be effective. The recoveries of PP1, PP2 and P-Tyr were $73.0,88.3$ and $71.5 \%$, respectively, whereas those of Glu-Glu and BDAs were suppressed to only below $10 \%$.
\end{abstract}

(Received May 30, 2007; Accepted September 5, 2007; Published November 10, 2007)

\section{Introduction}

The roles of organic phosphates, such as nucleotides, phosphopeptides and phosphoproteins, in biological processes are well recognized. ${ }^{1,2}$ To understand them, a method that permits a selective enrichment of trace amounts of the phosphates is desired. Immobilized metal ion affinity chromatography (IMAC) $)^{3}$ has been used for this purpose based on the strong interaction of phosphates with metal ions, such as $\mathrm{Fe}(\mathrm{III})^{4-7}$ and $\mathrm{Ga}(\mathrm{III}){ }^{8-10}$ A novel dinuclear zinc(II) complex, Phos-tag ${ }^{\circledR}$ was reported to be a highly selective IMAC sorbent for phosphates. ${ }^{11,12}$ On the other hand, we have found that titanium dioxide $\left(\mathrm{TiO}_{2}\right.$, titania) is a unique chromatographic sorbent, especially for the selective adsorbent of organic phosphates. ${ }^{13,14}$ We recently developed a column-switching high-performance liquid chromatography (HPLC) system consisting of a titania precolumn and an anion-exchange analytical column, and demonstrated its utility for the analysis of phosphopeptides ${ }^{15}$ and some phosphoproteins. ${ }^{16}$ Our findings attracted many researchers, and various types of column-switching HPLC systems equipped with a titania precolumn have been reported. ${ }^{17-20}$ However, problems are pointed out that both IMAC and titania adsorb other acidic compounds non-specifically.,7,18

In the present study, to search for more selective chemoaffinity sorbents for organic phosphates, we attempted to evaluate titanium (Ti) and some titanium oxides such as $\mathrm{TiO}$, $\mathrm{Ti}_{2} \mathrm{O}_{3}, \mathrm{Ti}_{3} \mathrm{O}_{5}$ and $\mathrm{TiO}_{1.98}$ as well as $\mathrm{TiO}_{2}$. The necessary conditions to eliminate the non-specific adsorption of acidic compounds other than phosphates were also studied using $\mathrm{Ti}$ as a novel chemo-affinity sorbent.

\footnotetext{
$\doteqdot$ To whom correspondence should be addressed.
}

\section{Experimental}

Chemicals

Ti (particle diameter, below $250 \mu \mathrm{m}$ ) was purchased from Wako Pure Chemical (Osaka, Japan) and $\mathrm{TiO}, \mathrm{Ti}_{2} \mathrm{O}_{3}, \mathrm{Ti}_{3} \mathrm{O}_{5}$ (the commercial name is "titanium oxide $\mathrm{S}$ " and contains considerable amounts of $\mathrm{Ti}_{4} \mathrm{O}_{7}$ ) and $\mathrm{TiO}_{1.98}$ (which is supplied as $\mathrm{TiO}_{2}$, but its actual formula is $\mathrm{TiO}_{1.98-1.99}$ and therefore we call it $\mathrm{TiO}_{1.98}$ ) were from E. Merck (Darmstadt, Germany). TiO (average particle diameter, $2 \mu \mathrm{m}$ ) was kindly donated by Toho Titanium (Tokyo, Japan). $O$-Phospho-L-tyrosine (P-Tyr) and L-tyrosine (L-Tyr) were obtained from Sigma (St. Louis, MA, USA). Phenyl phosphate (PhP) and phenylphosphonic acid (PhPN) were obtained from Nacalai Tesque (Kyoto, Japan). 1,2-, 1,3- and 1,4-benzenedicarboxylic acids (1,2-, 1,3- and 1,4BDAs; common names are phthalic acids) were purchased from Tokyo Kasei (Tokyo, Japan), and benzoic acid (BZA) and benzenesulfonic acid (BSA) were from Kanto Chemical (Tokyo, Japan) and Daiichi Chemicals (Tokyo, Japan), respectively. Diglutamic acid (Glu-Glu) was obtained from Peptide Institute (Osaka, Japan). Ile-Ser(p)-Val-Arg (PP1) and Gln-Ile-Ser(p)-Val-Arg (PP2) were prepared as described previously. ${ }^{15}$ Boric acid, $\mathrm{LiCl}, \mathrm{NaCl}$, NaF, methanol, acetonitrile (Kanto Chemicals) and trifluoroacetic acid (TFA, Nacalai Tesque) were used as received. Water was purified on a Milli RO-Milli Q system (Millipore, Bedford, MA, USA).

\section{Preparation of precolumns}

$\mathrm{TiO}, \mathrm{Ti}_{2} \mathrm{O}_{3}, \mathrm{Ti}_{3} \mathrm{O}_{5}$ and $\mathrm{TiO}_{1.98}$ were ground in ceramic mortors with pestles, and the fine particles obtained were passed through screens with sieve openings of 75 and $44 \mu \mathrm{m}$. Ti was directly passed through the screens. $\mathrm{TiO}_{2}$ was used as received. These particles were packed into stainless-steel tubes $(4.6 \mathrm{~mm}$ i.d. $\times 10$ 


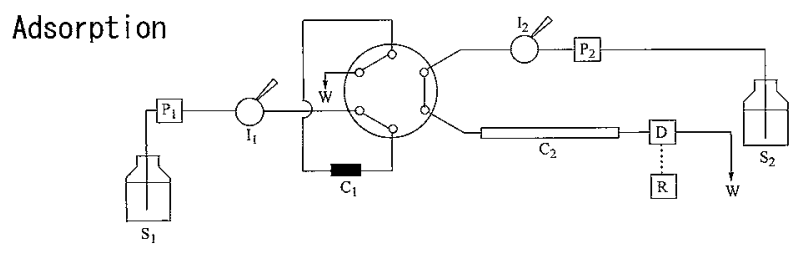

Elution

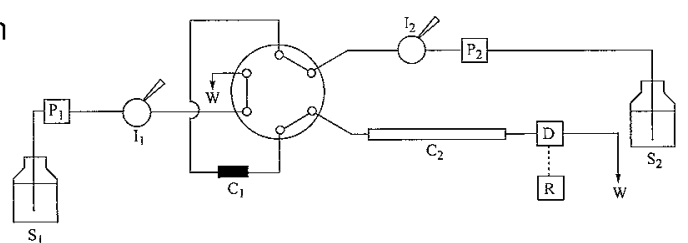

Fig. 1 Schematic diagram of the column-switching HPLC system using a Ti or titanium oxide precolumn. $\mathrm{P}_{1}$ and $\mathrm{P}_{2}$, pumps; $\mathrm{I}_{1}$ and $\mathrm{I}_{2}$, injectors; $\mathrm{C}_{1}, \mathrm{Ti}$ or titanium oxide precolumn $(4.6 \mathrm{~mm}$ i.d. $\times 10 \mathrm{~mm}$ ); $\mathrm{C}_{2}$, Asahipak NH2P-50-4E (4.6 mm i.d. $\left.\times 250 \mathrm{~mm}\right) ; \mathrm{S}_{1}$, sampleloading solution (flow rate, $0.5 \mathrm{ml} / \mathrm{min}$ ); $\mathrm{S}_{2}$, eluent $[0.05 \mathrm{M}$ borate buffer (pH 8.0) containing 80, 200, 400 or $500 \mathrm{mM} \mathrm{LiCl}$ ] (flow rate, $0.5 \mathrm{ml} / \mathrm{min})$; D, UV detector ( $215 \mathrm{~nm}$ ); R, integrator; $\mathrm{W}$, waste.

Table 1 Recoveries of test compounds by column-switching HPLC equipped with a titanium or titanium oxide precolumn

\begin{tabular}{lccccccc}
\hline & & \multicolumn{6}{c}{ Recovery, ${ }^{\mathrm{b}} \%$} \\
\cline { 3 - 8 } & Eluent $^{\mathrm{n}}$ & $\mathrm{TiO}_{2}$ & $\mathrm{Ti}$ & $\mathrm{TiO}$ & $\mathrm{Ti}_{2} \mathrm{O}_{3}$ & $\mathrm{Ti}_{3} \mathrm{O}_{5}$ & $\mathrm{TiO}_{1.98}$ \\
\hline P-Tyr & 1 & 81.2 & 85.7 & 93.6 & 88.7 & 95.8 & 91.0 \\
$\mathrm{PhP}$ & 1 & 95.6 & 90.5 & 99.9 & 92.3 & 102.5 & 90.7 \\
$\mathrm{PhPN}$ & 2 & 72.9 & 75.3 & 64.4 & 62.0 & 75.4 & 72.6 \\
$\mathrm{~L}-\mathrm{Tyr}$ & 1 & $\mathrm{ND}^{\mathrm{c}}$ & $\mathrm{ND}$ & $\mathrm{ND}$ & $\mathrm{ND}$ & $\mathrm{ND}$ & $\mathrm{ND}$ \\
$\mathrm{BSA}$ & 2 & $\mathrm{ND}$ & $\mathrm{ND}$ & $\mathrm{ND}$ & $\mathrm{ND}$ & $\mathrm{ND}$ & $\mathrm{ND}$ \\
$\mathrm{BZA}$ & 2 & 82.6 & $\mathrm{ND}$ & $\mathrm{ND}$ & $\mathrm{ND}$ & $\mathrm{ND}$ & $\mathrm{ND}$ \\
1,2-BDA & 3 & 104.4 & 94.6 & 108.3 & 45.4 & 93.9 & 90.6 \\
1,3-BDA & 3 & 98.3 & 26.7 & 31.7 & 10.5 & 26.6 & 29.6 \\
1,4-BDA & 3 & 119.2 & 38.0 & 55.9 & 13.5 & 54.0 & 62.4 \\
\hline
\end{tabular}

a. Eluent in $0.05 \mathrm{M}$ borate buffer (pH 8.0) containing LiCl: 1, 200; 2 , $500 ; 3,400 \mathrm{mM}$.

b. Mean of 2 experiments.

c. Not detected.

$\mathrm{mm}$ ) by a slurry method in methanol under aspiration. About $0.3-0.4 \mathrm{~g}$ of each material was packed into a separate stainlesssteel tube.

\section{Working standard solutions of test compounds}

Stock standard solutions of P-Tyr, PhP, PhPN, L-Tyr, BZA, BSA, BDAs, Glu-Glu, PP1 and PP2 were prepared at 1 or $10 \mathrm{mM}$ concentrations in water. The stock standard solutions were diluted with water or aqueous $0.015 \%$ TFA to prepare $10 \mu \mathrm{M}$ working standard solutions, except that P-Tyr was diluted to $5 \mu \mathrm{M}$.

\section{Column-switching HPLC analysis}

The column-switching HPLC system used here was essentially the same as that reported previously, ${ }^{15,16}$ except that precolumns packed with $\mathrm{Ti}$ or titanium oxides $(4.6 \mathrm{~mm}$ i.d. $\times 10$ $\mathrm{mm}$ ), and various sample-loading solutions were tested. A flow diagram of the system is shown in Fig. 1.

A $200-\mu 1$ aliquot of the sample solution was injected into the HPLC system from an injector, $\mathrm{I}_{1}$, (except that a $100-\mu \mathrm{l}$ aliquot of PTAs was injected) at the valve position of "Adsorption".

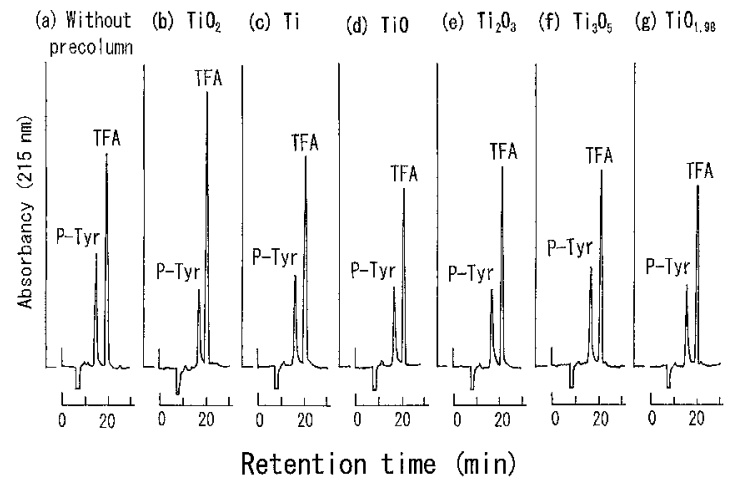

Fig. 2 Chromatograms of P-Tyr. An anion-exchange chromatogram without precolumn (a) and column-switching HPLC chromatograms with $\mathrm{TiO}_{2}$ (b), Ti (c), $\mathrm{TiO}$ (d), $\mathrm{Ti}_{2} \mathrm{O}_{3}$ (e), $\mathrm{Ti}_{3} \mathrm{O}_{5}$ (f) and $\mathrm{TiO}_{1.98}$ (g) precolumns. The sample-loading solution was $0.015 \%$ TFA and the eluent was $200 \mathrm{mM} \mathrm{LiCl}$ in $0.05 \mathrm{M}$ borate buffer ( $\mathrm{pH} \mathrm{8.0).} \mathrm{P-Tyr}$ was dissolved in $0.015 \%$ TFA at a $5 \mu \mathrm{M}$ concentration and a $200-\mu \mathrm{l}$ aliquot of the solution was injected into the HPLC system.

After $5 \mathrm{~min}$, the valve was changed to the position of "Elution", and any compound retained on the precolumn was desorbed by delivering the mobile phase with a back-flashing mode, subsequently separated on the anion-exchange column, and then detected spectrophotometrically at $215 \mathrm{~nm}$. For direct anionexchange HPLC without the precolumns, sample solutions were injected from an injector, $\mathrm{I}_{2}$.

\section{Results and Discussion}

Recovery of phosphates and other acidic compounds from Ti and titanium oxides using aqueous TFA as a sample-loading solution

The column-switching HPLC system used here (Fig. 1) was essentially the same as that reported previously dealing with titania as a precolumn packing material. ${ }^{15,16}$ Initially, according to the previous studies, aqueous $0.015 \%$ TFA was used as the sample-loading solution. The recoveries of obtained test compounds are summarized in Table 1, where the recoveries were determined based on the ratio of the peak areas obtained by direct anion-exchange HPLC and those of column-switching HPLC.

The recoveries of organic phosphates, $\mathrm{P}-\mathrm{Ty}$ and $\mathrm{PhP}$, were above $80 \%$ in all cases, and even in a phosphonic acid (PhPN) more than $60 \%$ recoveries were obtained. Typical chromatograms of P-Tyr are shown in Fig. 2. Figure 2a indicates the chromatograms of P-Tyr obtained by direct anionexchange HPLC, and Figs. $2 b-2 g$ are the results of the columnswitching HPLC. On the column-switching HPLC chromatograms, P-Tyr was clearly detected in all cases. These results suggest that the chemo-affinity to phosphate compounds is the characteristics for not only titania, but also a wide variety of titanium oxides and $\mathrm{Ti}$, itself, that suggests the utility of the materials as chemo-affinity sorbents for organic phosphates.

Among the acidic compounds other than phosphates listed in Table 1, L-Tyr and BSA were not retained and BZA was retained only on $\mathrm{TiO}_{2}(82.6 \%)$. Typical chromatograms of L-Tyr are shown in Fig. 3a-3g. L-Tyr detected by the direct anion-exchange HPLC (Fig. 3a) completely disappeared on the column-switching HPLC chromatograms in all cases (Fig. 3b-3g). However, BDAs were adsorbed on all of the sorbents with recoveries of $10.5-119.2 \%$. Particularly $\mathrm{TiO}_{2}$ adsorbed three BDA isomers 
almost quantitatively. It has been reported that some acidic compounds other than phosphates are adsorb non-specifically on IMAC sorbent ${ }^{4,7}$ and $\mathrm{TiO}_{2}{ }^{18}$ To eliminate the adsorption of acidic compounds, modifications of the sample-loading solution were attempted in following studies using a $\mathrm{Ti}$ precolumn, because it gave higher recoveries of phosphate compounds (Table 1).

Effects of the sample-loading solution on the selectivity of a Ti precolumn

Phosphopeptides PP1 and PP2 as phosphate compounds and Glu-Glu and three BDA isomers as other acidic compounds were tested. Solutions of various organic acids, inorganic acids and inorganic salts were tested as sample-loading solutions. The recoveries of the obtained test compounds are summarized in Table 2.

Aqueous solutions of TFA and $\mathrm{HClO}_{4}$ gave good recoveries of PP1 and PP2, but caused unfavorable adsorptions of Glu-Glu and 1,2-BDA. Kokubu et al. ${ }^{7}$ reported that when Fe(III)-IMAC

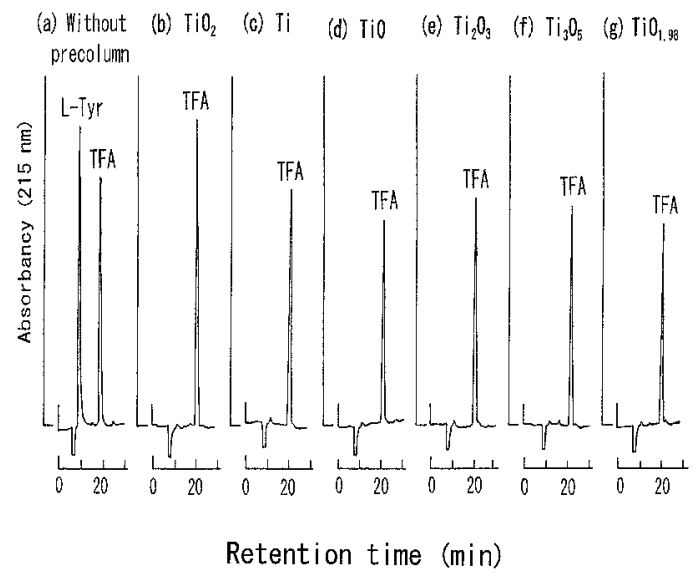

Fig. 3 Chromatograms of L-Tyr. An anion-exchange chromatogram without precolumn (a) and column-switching HPLC chromatograms with $\mathrm{TiO}_{2}$ (b), $\mathrm{Ti}$ (c), $\mathrm{TiO}$ (d), $\mathrm{Ti}_{2} \mathrm{O}_{3}$ (e), $\mathrm{Ti}_{3} \mathrm{O}_{5}$ (f) and $\mathrm{TiO}_{1.98}(\mathrm{~g})$ precolumns. The sample-loading solution was $0.015 \%$ TFA and the eluent was $200 \mathrm{mM} \mathrm{LiCl}$ in $0.05 \mathrm{M}$ borate buffer (pH 8.0). L-Tyr was dissolved in $0.015 \%$ TFA at a $10 \mu \mathrm{M}$ concentration and a $200-\mu \mathrm{l}$ aliquot of the solution was injected into the HPLC system. was performed to separate phosphopeptides, acetonitrile solutions of TFA were useful to eliminate the non-specific adsorption of non-phosphopeptides onto the IMAC sorbent. Thus, acetonitrile solutions of TFA and $\mathrm{HClO}_{4}$ were tested in this work as well. However, their use was effective for eliminating the adsorption of BDAs, but not for Glu-Glu. Rather than acetonitrile solutions of the acids, $50 \%$ aqueous acetonitrile gave good selectivity. The recovery of Glu-Glu was only $3.3 \%$ and the adsorption of BDAs was essentially negligible. However, remarkable peak broadenings of PP1 and PP2 were observed, and therefore any further examination on the use of aqueous acetonitrile was abandoned.

Organic acids and boric acid may be expected to show an expelling ability toward carboxylic acids adsorbed onto $\mathrm{Ti}$, owing to their bi-functionality, leading to higher affinity to Ti than carboxylic acids. Taurine, glycine, $\beta$-alanine and glycolic acid were tested as typical organic acids, and moderate selectivity was observed. For example, taurine gave the $60-$ $85 \%$ recoveries of PP1 and PP2, while the recovery of Glu-Glu was $20 \%$ and those of BDAs were below $10 \%$. However, these results were not so satisfactory. On the other hand, boric acid was found to give good recoveries of PP1 (73\%) and PP2 $(94 \%)$, and effectively suppressed the adsorption of other acidic compounds, except that the recovery of 1,2-BDA was about $30 \%$. The adsorption of 1,2-BDA was not avoided, even when the boric acid concentrations were increased up to $100 \mathrm{mM}$.

On the contrary to the above experiments, $\mathrm{NaCl}$ was then tested, because if the adsorption of phosphate compounds onto Ti is based on a specific affinity, whereas the adsorption of GluGlu and BDAs onto Ti is supposed to be directed by the usual ionic interaction, inorganic salts are considered to be useful to suppress the latter interaction. $\mathrm{NaCl}(10 \mathrm{mM})$ was highly effective to suppress the adsorption of Glu-Glu and BDAs, though unfortunately the recoveries of PP1 and PP2 were considerably lowered.

Based on the above findings, we examined the combined use of boric acid and $\mathrm{NaCl}$ while anticipating a complementary action of the advantages of boric acid and $\mathrm{NaCl}$. Details are discussed below.

Examination of the combined use of boric acid and $\mathrm{NaCl}$ as the components of sample-loading solution

Initially, the recoveries of PP1, PP2, Glu-Glu and BDAs were studied using sample-loading solutions of varying

Table 2 Effect of sample-loading solutions on the recoveries of test compounds by column-switching HPLC equipped with a Ti precolumn

\begin{tabular}{|c|c|c|c|c|c|c|}
\hline \multirow{2}{*}{ Solution } & \multicolumn{6}{|c|}{ Recovery, ${ }^{\text {a }} \%$} \\
\hline & $\mathrm{PP} 1^{\mathrm{b}}$ & $\mathrm{PP} 2^{\mathrm{b}}$ & Glu-Gluc & $1,2-\mathrm{BDA}^{\mathrm{d}}$ & $1,3-\mathrm{BDA}^{\mathrm{d}}$ & $1,4-\mathrm{BDA}^{\mathrm{d}}$ \\
\hline $0.015 \%$ TFA & 90.6 & 100.9 & 67.7 & 95.1 & 7.9 & 43.4 \\
\hline $0.015 \% \mathrm{TFA} / \mathrm{CH}_{3} \mathrm{CN}$ & 91.8 & 96.8 & 97.3 & 4.4 & 0.8 & 1.3 \\
\hline $10 \mathrm{mM} \mathrm{HClO}_{4}$ & 73.5 & 100.0 & 21.3 & 83.7 & 2.6 & 5.9 \\
\hline $10 \mathrm{mM} \mathrm{HClO}_{4} / \mathrm{CH}_{3} \mathrm{CN}$ & 75.8 & 111.4 & 17.1 & 2.6 & 0.7 & 0.9 \\
\hline 2 mM Glycine & 55.5 & 77.8 & 15.2 & 6.1 & $\mathrm{ND}^{\mathrm{e}}$ & 0.2 \\
\hline $2 \mathrm{mM} \beta$-Alanine & 76.7 & 92.4 & 21.0 & 7.9 & ND & ND \\
\hline 2 mM Glycolic acid & 73.4 & 73.3 & 16.6 & 9.9 & 0.2 & 0.6 \\
\hline 2 mM Taurine & 64.3 & 85.9 & 19.2 & 9.6 & ND & 0.8 \\
\hline $10 \mathrm{mM}$ Boric acid & 73.5 & 94.3 & 10.5 & 29.7 & ND & 0.4 \\
\hline $10 \mathrm{mM} \mathrm{NaCl}$ & 37.9 & 65.9 & 2.1 & ND & ND & ND \\
\hline $50 \% \mathrm{CH}_{3} \mathrm{CN}$ & 52.4 & 63.4 & 3.3 & ND & ND & ND \\
\hline
\end{tabular}

a. Mean of 2 experiments. b. Eluent, $80 \mathrm{mM} \mathrm{LiCl}$ in $0.05 \mathrm{M}$ borate buffer ( $\mathrm{pH} 8.0$ ). c. Eluent, $200 \mathrm{mM} \mathrm{LiCl}$ in $0.05 \mathrm{M}$ borate buffer (pH 8.0). d. Eluent, $400 \mathrm{mM} \mathrm{LiCl}$ in $0.05 \mathrm{M}$ borate buffer ( $\mathrm{pH} 8.0$ ). e. Not detected. 


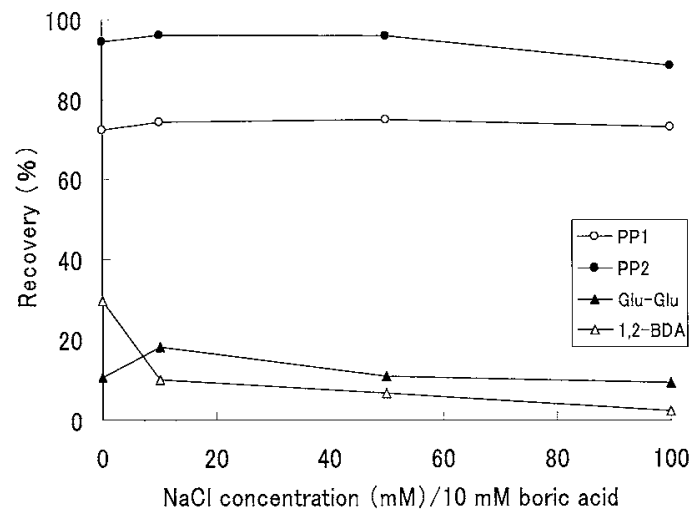

Fig. 4 Effect of the $\mathrm{NaCl}$ concentration in $10 \mathrm{mM}$ boric acid on the recoveries of PP1, PP2, Glu-Glu and 1,2-BDA. Aliquots (200- $\mu$ l) of aqueous $10 \mu \mathrm{M}$ PP1, PP2, and Glu-Glu solutions or a $100-\mu \mathrm{l}$ aliquot of aqueous $10 \mu \mathrm{M}$ BDAs solution were injected into the HPLC system.

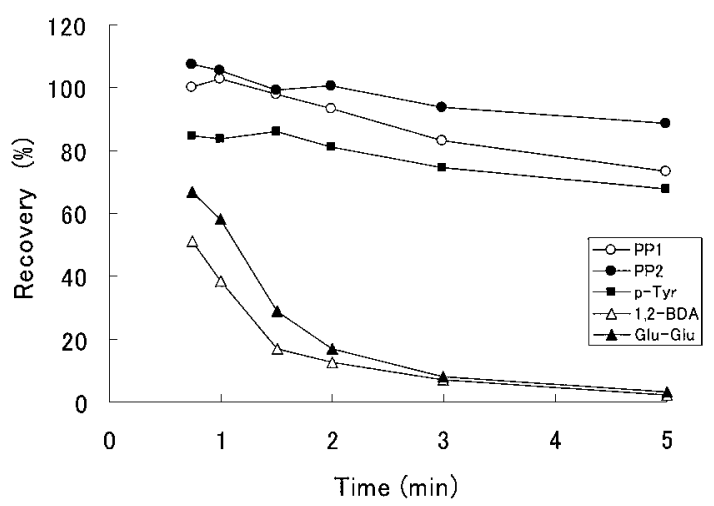

Fig. 5 Effect of the time interval on the recoveries of PP1, PP2, P-Tyr, Glu-Glu and 1,2-BDA after injection of those onto a Ti precolumn. Aliquots $(200-\mu \mathrm{l})$ of aqueous $10 \mu \mathrm{M}$ PP1, PP2, and GluGlu solutions or a $100-\mu \mathrm{l}$ aliquot of aqueous $10 \mu \mathrm{M}$ BDAs solution were injected into the HPLC system, and after defined times, the sixport valve was switched.

concentrations of $\mathrm{NaCl}$ solutions in $10 \mathrm{mM}$ boric acid. As shown in Fig. 4, 70-80\% recoveries of PP1 and PP2 were obtained with $\mathrm{NaCl}$ concentrations of up to $100 \mathrm{mM}$, whereas those of Glu-Glu and 1,2-BDA decreased with increasing the $\mathrm{NaCl}$ concentrations. At $100 \mathrm{mM} \mathrm{NaCl}$, the recoveries of GluGlu and 1,2-BDA were 9.1 and 2.2\%, respectively. 1,3- and 1,4-BDAs were not detected under these conditions. Next, the effects of the time intervals until column-switching after injection of the test compounds on those recoveries were studied. The results are shown in Fig. 5. Although, a slight lowering in the recoveries of PP1, PP2 and P-Tyr was observed over the prolonged switching times, even after $5 \mathrm{~min}$, their recoveries were $73.0,88.3$ and $71.5 \%$, respectively. However, the recoveries of Glu-Glu and 1,2-BDA decreased markedly with prolonged switching times, and reached to a few $\%$ after 3 min. Typical chromatograms obtained by using $100 \mathrm{mM} \mathrm{NaCl}$ in $10 \mathrm{mM}$ boric acid as sample-loading solution are shown in Fig. 6, which obviously prove the utility.

These results support the above-mentioned hypothesis that the adsorption of phosphate compounds onto $\mathrm{Ti}$ is based on a specific affinity, whereas Glu-Glu and BDAs are mainly retained by the usual ion-exchange mechanism. Some specific
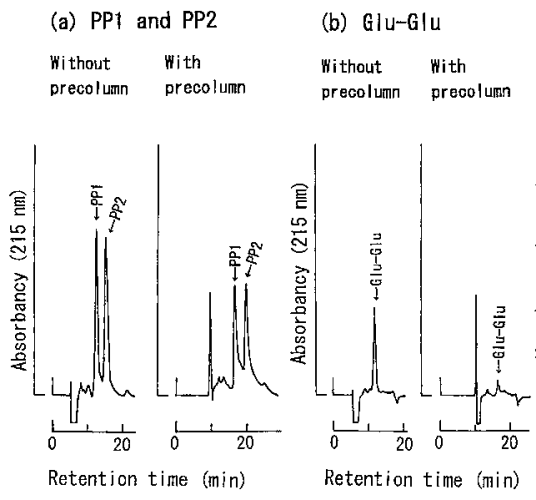

(c) PTAs

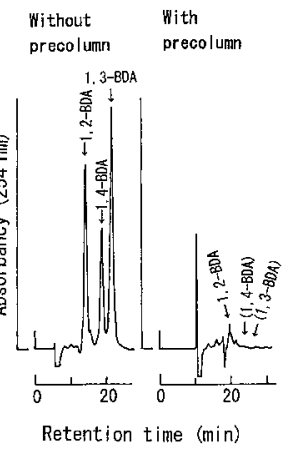

Fig. 6 Chromatograms of PP1 and PP2 (a), Glu-Glu (b) and BDAs (C). Anion-exchange chromatograms without precolumn and column-switching HPLC chromatograms with a Ti precolumn are shown. The sample-loading solution was $100 \mathrm{mM} \mathrm{NaCl}$ in $10 \mathrm{mM}$ boric acid. The eluents used were the same as those listed in Table 2. Aliquots $(200-\mu \mathrm{l})$ of aqueous $10 \mu \mathrm{M}$ PP1 and PP2, and Glu-Glu solutions or a $100-\mu 1$ aliquot of aqueous $10 \mu \mathrm{M}$ BDAs solution were injected into the HPLC system.

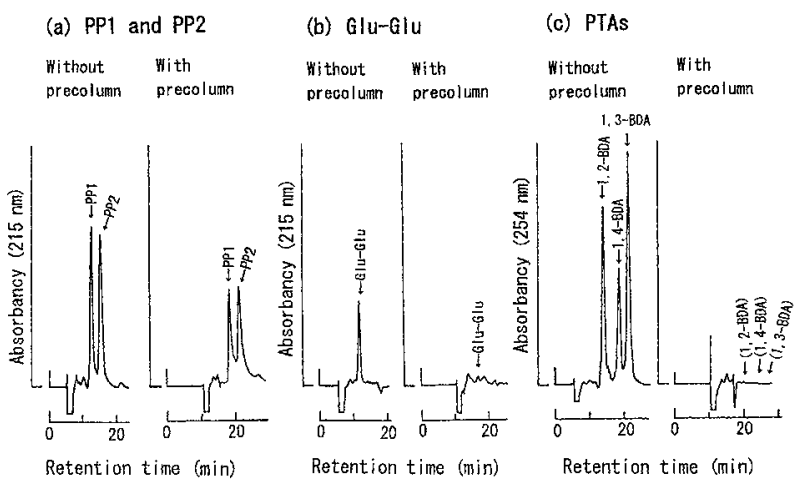

Fig. 7 Chromatograms of PP1 and PP2 (a), Glu-Glu (b) and BDAs (C). Anion-exchange chromatograms without precolumn and column-switching HPLC chromatograms with a Ti precolumn are shown. The sample-loading solution was $1 \mathrm{mM} \mathrm{NaF}$ in $10 \mathrm{mM}$ boric acid. All other conditions are the same as those of Fig. 6.

interaction between $\mathrm{Ti}$ atoms and phosphate $\mathrm{OH}$ groups is expected, but further speculation is difficult at the present time. The reason why higher recoveries of PP1 and PP2 were obtained at higher concentrations of $\mathrm{NaCl}$ when used as a boric acid solution instead of an aqueous solution is also unknown. The $\mathrm{pH}$ of the solutions seemed not to be very critical, e.g. the $\mathrm{pH}$ values of $10 \mathrm{mM} \mathrm{NaCl}, 10 \mathrm{mM}$ boric acid and $100 \mathrm{mM}$ $\mathrm{NaCl}$ in $10 \mathrm{mM}$ boric acid were 6.1, 6.1 and 5.6, respectively.

The above facts induce further interest to use other halide ions. $\mathrm{NaBr}$ was not suitable to use owing to the UV absorptivity of bromide ion. The use of $\mathrm{NaF}$ was found to give a much more drastic effect. As shown in Fig. 7, NaF exhibited a favorable effect only at $1 \mathrm{mM}$ concentration in a $10 \mathrm{mM}$ boric acid solution. Under the conditions, the recovery of Glu-Glu was $4.6 \%$, and all BDA isomers were not detected, whereas the recoveries of PP1 $(71.7 \%)$ and PP2 $(88.7 \%)$ were acceptable. These results were quite primitive, but clearly demonstrated the potential of $\mathrm{Ti}$ for the highly selective enrichment of phosphate compounds.

Titania has been appreciated as a selective sorbent for 
organic phosphates, especially phosphopeptides ${ }^{15,17}$ and phosphoproteins. ${ }^{16,18-20}$ Quite recently, titania was used as a tool for the analysis of phosphopeptides in the course of studying cell signaling mechanisms. ${ }^{21}$ Through the present study dealing with the evaluation of $\mathrm{Ti}$ and some titanium oxides, $\mathrm{Ti}$ was proposed to be a novel candidate for a more selective chemoaffinity sorbent, rather than titania. The proposed system seems to be useful for practical applications, such as the analysis of phosphorylation sites in phosphoproteins.

\section{Acknowledgements}

The work was supported in part by a Grant-in-Aid for Scientific Research (No. 18659011) from Japan Society for the Promotion of Science.

\section{References}

1. T. Hunter, Cell, 2000, 100, 113.

2. T. Pawson and J. D. Scott, Trends Biochem. Biosci., 2005, 30, 286.

3. G. L. Corthals, R. Aebersold, and D. R. Goodlett, Methods Enzymol., 2005, 405, 66.

4. G. Muszynska, G. Dobrowolska, A. Medin, P. Ekman, and J. O. Porath, J. Chromatogr., 1992, 604, 19

5. C. S. Raska, C. E. Parker, Z. Dominski, W. F. Marzluff, G. L. Glish, R. M. Pope, and C. H. Borchers, Anal. Chem. 2002, 74, 3429.

6. R. Tuytten, F. Lemiere, W. Van Dongen, H. Slegers, R. P.
Newton, and E. L. Esmans, J. Chromatogr., B, 2004, 809, 189.

7. M. Kokubu, Y. Ishihama, T. Sato, T. Nagasu, and Y. Oda, Anal. Chem., 2005, 77, 5144.

8. M. C. Posewitz and P. Tempst, Anal. Chem., 1999, 71, 2883.

9. D. Hirschberg, T. Jagerbrink, J. Samskog, M. Gustafsson, M. Stahlberg, G. Alvelius, B. Husman, M. Carlquist, H. Jornvall, and T. Bergman, Anal. Chem., 2004, 76, 5864.

10. E. H. Seeley, L. D. Riggs, and F. E. Regnier, $J$. Chromatogr., B, 2005, 817, 81 .

11. A. Yamada, H. Takeda, E. Kinoshita, and T. Koike, Chromatography, 2003, 24(Suppl. 2), 103.

12. E. Kinoshita, M. Takahashi, H. Takeda, M. Shiro, and T. Koike, Dalton Trans., 2004, 1189.

13. H. Matsuda, H. Nakamura, and T. Nakajima, Anal. Sci., 1990, 6, 911.

14. Y. Ikeguchi and H. Nakamura, Anal. Sci., 1997, 13, 479.

15. A. Sano and H. Nakamura, Anal. Sci., 2004, 20, 565.

16. A. Sano and H. Nakamura, Anal. Sci., 2004, 20, 861.

17. I. Kuroda, Y. Shintani, M. Motokawa, S. Abe, and M. Furuno, Anal. Sci., 2004, 20, 1313.

18. M. W. H. Pinkse, P. M. Uitto, M. J. Hilhorst, B. Ooms, and A. J. R. Heck, Anal. Chem., 2004, 76, 3935.

19. A. Schlosser, J. T. Vanselow, and A. Kramer, Anal. Chem., 2005, 77, 5243

20. K. Hata, H. Morisaka, K. Hara, J. Mima, N. Yumoto, Y. Tatsu, M. Furuno, N. Ishizuka, and M. Ueda, Anal. Biochem., 2006, 350, 292.

21. J. V. Olsen, B. Blagoev, F. Gnad, B. Macek, C. Kumar, P. Mortensen, and M. Mann, Cell, 2006, 127, 635. 